\title{
Driver distraction by smartphone use (WhatsApp) in different age groups
}

\author{
OrtizC.*, Ortiz-PeregrinaS., CastroJ.J., Casares-LópezM., SalasC. \\ Department of Optics, Laboratory of Vision Sciences and Applications, University of Granada, Granada, 18071, Spain
}

\section{A R T ICLE INFO}

\section{Keywords:}

Smartphone

WhatsApp

Visual function

Driving performance

Distraction

Age

\begin{abstract}
A B S T R A C T
This paper investigates the effect that texting with WhatsApp, one of the most common applications for instant messaging, exerts on driving performance. Because distracted driving also affects older drivers, who can have seriously compromised vision, we also analysed the associations between visual-function parameters and driving performance. A total of 75 drivers, experienced in sending WhatsApp messages ( $\geq 10$ WhatsApp messages/week), participated in this study and were divided into four age categories. Visual-function tests included contrast sensitivity with and without glare, retinal straylight and objective assessment of optical quality. Simulated driving performance was assessed under a baseline driving condition (without distraction) as well as a texting condition (WhatsApp messages) while driving. The participants used their own mobile phone. Lastly, objective results of driving performance were compared with subjective self-report data from the Driver Behaviour Questionnaire (DBQ). The analysis indicated that functional changes occurring with age, such as a lower contrast sensitivity and greater retinal straylight, were correlated with a higher number of collisions, longer distances driven outside the lane, and greater standard deviation of lateral position (SDLP). The results showed a significant main effect of age for the driving-performance parameters. Also, compared to the baseline, texting WhatsApp messages while driving worsens driving performance for all age groups, most notably among older participants. Thus, the older drivers' SDLP was $\sim 14 \%$ higher than that for the baseline average of all the other drivers and rose to $29 \%$ under distraction, reflecting the impact of secondary tasks. The negative effect of the use of the smartphone during driving was also reflected in the number of collisions, with a greater risk of accidents in all the groups of drivers (by $8.3 \%$ for young adults, $25.0 \%$ for adults, $80.5 \%$ for middle-aged adults, and $134.5 \%$ for older drivers). Lastly, participants' subjective responses indicated that younger drivers (18-24 years) had a higher risk of deliberately violating safe driving practices $(\mathrm{p}<0.05)$. The present study demonstrates that texting WhatsApp messages while driving significantly impairs the ability to drive safely, with older drivers being the group most adversely affected. It would be recommendable to include other nonstandard vision tests, which have shown associations with driving performance, in the examination for driver licensing. This would help raise the awareness of older drivers concerning their visual limitations, permitting them to adopt compensatory measures to improve their driving safety. Nevertheless, it is also necessary to raise awareness among the younger drivers of the risks involved in behaviour behind the wheel.
\end{abstract}

\section{Introduction}

Distracted driving is one of the major concerns in terms of road safety today. According to the Spanish General Directorate of Traffic (DGT), 35\% of fatal crashes were caused by driver distraction in 2015 (Dirección General de Tráfico, 2016). In Canada, data from 2003 to 2007 showed that $10.7 \%$ of all drivers injured were distracted at the time of the crash (World Health Organization, 2011). Data from NHTSA's Fatality Analysis Reporting System (FARS) indicated that, in the United States, $10 \%$ of all fatal crashes and $15 \%$ of injury crashes in 2015 were reported as distraction-affected accidents (Report No. DOT HS 812 381). This level seems to persist.

One of the main causes of driver distraction is mobile-phone use, mostly for texting (Wilson and Stimpson, 2010). Until a few years ago, driving distraction from phones was limited to calls or SMS (Short Message Service). However, it has changed with the smartphone's emergence. Smartphones enable us to access the Internet, check e-mails, and social media or converse with applications such as WhatsApp, one of the most common applications for instant messaging at no cost. The growth of this application has been exponential since its introduction

\footnotetext{
* Corresponding author at: University of Granada, Department of Optics, Edificio Mecenas, Av. Fuentenueva s/n, Granada, 18071, Spain.

Email address: ortizh@ugr.es (C. Ortiz)
} 
only eight years ago, reaching 1 billion users (https://whatsapp.com). In Spain, according to DGT, $89 \%$ of all smartphone owners use WhatsApp in their devices and 53\% use it occasionally for texting while driving, despite this practice being banned (Dirección General de Tráfico, 2016).

The majority of studies that have investigated the mobile-phone use on driving performance have focused on young drivers, because they are the first group in distracted driving fatalities. Results in several studies indicated that young drivers (from 18 to $21 \mathrm{yrs}$.), when text messaging, spent up to $400 \%$ more time not looking at the road than when not texting, with variability in lane position rising to 50\% (Hosking et al., 2009). Also, the probability of being involved in an accident increased between 1.7- and 2-fold, compared to free driving (Yannis et al., 2016), with the $86 \%$ of the collisions occurred at the time of the dual task (Drews et al., 2009).

Distracted driving is also affected by driver age. Although older drivers show less distracted incidences while driving, they are not exempt. Cognitive, visual, and motor declines imply additional risk in distracted driving behaviour. Romoser et al. (2013) indicated that older drivers (from 72 to 87 yrs.) look less than younger drivers (from 25 to 55 yrs.) towards other areas where hazards are most likely. Also, Rumschlag et al. (2015) reported that the percent of subjects exhibiting lane excursions while texting increased with driver age group. However, the highest age of this sample was 59 years, and therefore some of the older drivers who used instant messaging applications were not studied.

In another study, Pope et al. (2017) analysed data collected with the "Distracted Driving Behaviour Questionnaire". Their results showed that distracted driving happens in drivers of all ages. According to Deshmukh (2015), the WhatsApp user's age distribution is: 18\% between 18-25 years, $29 \%$ between $26-35$ years, $24 \%$ between $36-45$ years, $11 \%$ between $46-55$ years, $13 \%$ between $56-65$ years and 5\% over 65 years. Hence, today, a significant proportion of people over 55 are regular users of instant messaging applications and this proportion will augment given that older adults are increasingly accepting new technologies (Mitzner et al., 2010) and that drivers who are now more frequent users will be older in a few years.

Texting and driving are both mainly visual tasks. One of the most important causes of the vulnerability in older drivers is vision as it is one of the most critical sensory mechanisms in the driving task. Aging causes a series of physiological changes in ocular structures that imply a worsening in visual performance and optical quality (Artal et al., 1993; Martínez-Roda et al., 2016; Owsley et al., 1983). This worsening can be significant in later adulthood even when the visual acuity is much greater than the minimum limit required by driving regulations (Ortiz et al., 2013). Older drivers often mention night-time driving difficulties with oncoming headlight glare being a particular problem, likely due to increased intraocular scatter from age-related changes in the lens and ocular media. The most common visual test for driver licensing is the measurement of high-contrast visual acuity, but this visual function has not shown strong correlations with driving ability (Owsley and McGwin, 2010), making it necessary to evaluate the visual function with other nonstandard vision tests. Szlyk et al. (1995) found a significantly poorer driving performance in older drivers (from 50 to 83 yrs.) with and without visual impairment compared to young drivers (from 19 to 49 yrs.) when assessed with a driving simulator. One visual function that has shown a significant association with driving is contrast sensitivity (Fraser et al., 2013; Freeman et al., 2006; Owsley et al., 2001) but in most cases this visual function is not tested before the driver license is issued. In fact, when contrast sensitivity becomes severely impaired due to cataracts in older drivers, crash risk increases even when it affects only one eye (Owsley et al., 2001). However, contrast sensitivity not only decreases with ocular pathologies, but it also undergoes an age-related decline (Owsley et al., 1983). As a result, older drivers have less visual-discrimination capacity in such a way that signals, pedestrians or traffic lights could go undetected. Older drivers also have a narrower useful field of view (UFV). Thus, the study conducted by Bromberg et al. (2012) has shown that, despite reducing the driving speed, elderly drivers ( $>65$ yrs.) may still encounter problems in detecting pedestrians that appear outside the centre of their UFV. These visual changes also affect the secondary task in distracted driving, requiring greater driver attention and, therefore, making this dual task riskier. Chaparro et al. (2005) concluded that older drivers (mean age $=69.2$ yrs.) identified significantly fewer road signs and drove more slowly than did the younger participants (mean age $=27.3$ yrs.), and this was exacerbated for the visual dual-task condition. Other studies have reported similar results (Shinar et al., 2005). In recent years, interest in vision in relation to driving has intensified because we have no enough evidence concerning the visual functions that are most involved in driving performance.

For everything indicated above, we hypothesize that instant messaging use, which is becoming steadily more common among drivers of all ages, has a negative effect on driving performance and this effect could be worse in older drivers due to the age-related visual impairment.

Thus, the purpose of the present study was to compare the effect of new forms of communication (e.g. texting WhatsApp messages) on driving performance through different age groups, covering all ages of instant messaging applications users, and correlate it with different visual parameters. This is especially important because other nonstandard vision tests could be needed to guarantee adequate visual requirements to get a driving license and thus to promote driving safety as much as possible. A secondary aim was to compare the results from a driver simulator (objective data) with self-report data from distracted-behaviour surveys in all age groups (subjective information).

\section{Material and methods}

\subsection{Participants}

A total of 75 drivers (53 male and 22 female subjects) participated in this study. All were in good general health without any ocular disease and having best-corrected visual acuity equal to or better than $20 / 25$ in both eyes. They were active drivers with a valid driving license for at least one year, who reported that they drove regularly (at least $1000 \mathrm{~km}$ in the last year), and had prior experience using a mobile phone while driving. All participants used WhatsApp as a common form of communication and they can be considered experienced in sending WhatsApp messages ( $\geq 10$ WhatsApp messages/week). Subjects were divided in four age categories: 20 young adults $18-24$ years old $(22.4 \pm 1.4$ years), 20 adults $25-39$ years old ( $30.2 \pm 4.2$ years), 20 middle-aged adults $40-54$ years old ( $46.6 \pm 3.6$ years), and 15 older adults more than 55 years old $(61.3 \pm 4.1$ years).

Finally, prior to participating in the study, all the drivers signed a written informed consent in accordance with the Helsinki Declaration (World Medical Association Declaration of Helsinki, 2001).

\subsection{Visual and optical performance}

\subsubsection{Contrast-sensitivity function}

The contrast-sensitivity function (CSF) reflects the sensitivity of the visual system, not only regarding size but also contrast. The experimental procedure for determining the CSF consists of measuring the contrast threshold (i.e. the contrast required to see a visual target reliably on a uniform background). The inverse of the contrast threshold as a function of spatial frequency is the contrast-sensitivity function. The CSF was measured, for all participants monocularly and binocularly 
with their best correction, with the CSV-1000 test (VectorVision, Ohio, USA) at $2.5 \mathrm{~m}$ (Fig. 1a.). This test has been demonstrated to be a reliable tool for measuring contrast sensitivity (Pomerance and Evans, 1994). The chart presents four rows, each corresponding to one of four spatial frequencies: 3, 6, 12, and 18 cycles/degree (cpd). Each row presents 17 circular patches. The first patch in the row presents a very high contrast grating in the far left of the row. The remaining 16 patches appear in eight columns presented across the row. Each column presents a grating patch, and the other patch is blank. The patches that present gratings have descending contrast moving from the left to right across each row. The subject's task consisted of indicating whether the grating appeared in the top patch or the bottom patch for each column. The contrast level of the last correct response was considered the contrast threshold. Before the data were recorded, each observer underwent three training sessions to minimize learning effects. More information on this visual test can be found elsewhere (Pomerance and Evans, 1994).

\subsubsection{Contrast glare tester}

Driver safety and night-time driving difficulties have been associated with glare sensitivity (Kimlin et al. 2017). This disability glare is the loss of retinal image contrast as a result of intraocular light scatter or straylight, which is caused by imperfections in the optical media (Aslam et al., 2007). Contrast sensitivity with and without the presence of glare were determined with the CGT-1000 (Takagi, Japan) (Fig. 1b.). The test is conducted at a distance of $35 \mathrm{~cm}$ from the screen. Contrast sensitivity is measured at six target sizes: $6.3^{\circ}, 4.0^{\circ}, 2.5^{\circ}, 1.6^{\circ}$, $1.0^{\circ}$, and $0.7^{\circ}$. The contrast threshold is presented at 13 contrast levels (from 0.01 to 0.64 contrast). The initial presentation is at maximal contrast with "seen" targets being followed by the same size target presented at the next lower contrast level (method of descending limits paradigm). The threshold is determined by the lowest contrast target seen and contrast levels were converted to log CS for statistical analysis
(Pesudovs, 2007). Each subject was tested monocularly and with spectacle correction when necessary.

Glare testing follows CS testing. The device has 8 glare sources arranged around the stimulus that are activated automatically to assess the contrast sensitivity with a simultaneous glare. The stimulus, a dark ring on a light background, had a duration of $0.8 \mathrm{~s}$ with an interval of $1 \mathrm{~s}$ between presentations. The medium glare setting $\left(20000 \mathrm{~cd} / \mathrm{m}^{2}\right)$ was used. The subject's task consisted of pressing a button when the stimulus was detected. More information on this visual test can be found elsewhere (Pesudovs, 2007).

\subsubsection{Retinal straylight measurements}

As mentioned above, optical imperfections of the eye cause light scattering, resulting in a loss of retinal-image contrast. To measure this retinal straylight for each eye, we used the "compensation comparison" method with a commercial device, the C-Quant meter (Oculus DG, Germany) (Fig. 1c). The method consists of a series of concentric rings. The smallest ring - the test field - is divided into two halves, which the subject is asked to look at while a concentric ring flickers with varying intensity and frequency, making it essentially a photopic test, in which this concentric ring would be the straylight source. The flickering of the straylight source induces a certain amount of perceived flickering in the test field. The subject is asked to compare the two halves of the test field, and to indicate which side has stronger flickering by pressing a button (Coppens et al., 2006). Three consecutive measurements were taken monocularly for each subject. The measurements were taken in a darkened and quiet room and the straylight parameter was expressed in a logarithmic scale as $\log (s)$. Higher values indicate more straylight and more sensitivity to glare and thus a more compromised visual function. Straylight increases with age in the perfectly healthy eye, reaching $\sim 1.40 \log (s)$ for subjects 75 years and over (Michael et al., 2009). More information can be found elsewhere (van den Berg et al., 2006).

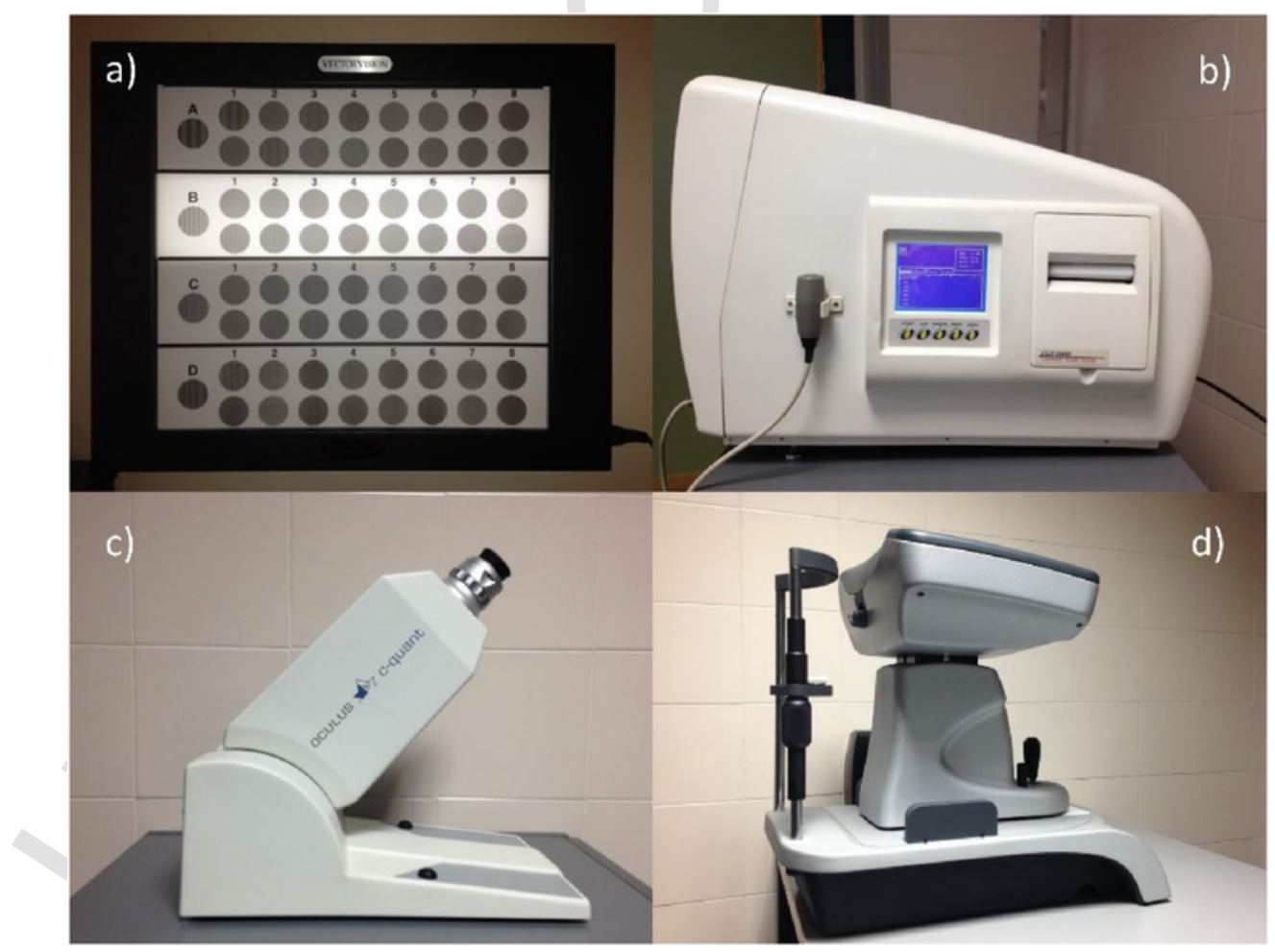

Fig. 1. Optical instruments used for evaluating visual and optical performance: a) CSV-1000 test, b) CGT-1000 test, c) C-Quant meter, d) OQAS II device. 


\subsubsection{Optical quality}

To evaluate the optical quality, we took data for an OSI (Objective Scattering Index) using the OQAS II (Optical Quality Analysis System II, Visiometrics SL, Tarrasa, Spain), an optical system based on the double-pass technique (Vilaseca et al., 2010) (Fig. 1d). This objective device is useful in older patients for measuring the effect of higher-order aberrations and the loss of ocular transparency caused by aging, this determining the quality of the retinal image.

The OSI is a parameter that enables the objective quantification of the intraocular scattering. OSI is computed as the ratio of the amount of light within an annular area of 12 and $20 \mathrm{~min}$ of arc (inner and outer radii) and that recorded within one minute of arc of the central peak in the acquired double-pass image. For a younger person with healthy eyes, normal OSI values are lower than 0.5; between 1.4 and 4 for eyes with an early cataract, and greater than 4 for eyes with a mature cataract (Martínez-Roda et al., 2011). Data were taken from both eyes with no pupil dilation to maintain natural conditions. More information on this device can be found elsewhere (Diaz-Douton et al., 2006; Vilaseca et al., 2010)

\subsection{Driving simulator}

The virtual visual environment was presented on three High Definition 27" screens (resolution of $1920 \times 1080$ pixels) with an $180^{\circ}$ field of view. The driving simulator consists of a car seat of the model BC Corona ASI320325R, which is anchored to the structure of the simulator, and a steering wheel (rotation of $900^{\circ}$, equivalent to two and a half turns of the wheel), a gearshift of six speeds plus reverse and pedals (accelerator, brake, and clutch) model Logitech G27 Racing Wheel (Logitech International S.A., Lausanne, Switzerland). The software SIMAX DRIVING SIMULATOR v4.0.8 BETA was used for driving simulation (SimaxVirt S.L., Pamplona, Spain).

Participants drove an itinerary of approximately $12.5 \mathrm{Km}$, which required about $15 \mathrm{~min}$ to complete when abiding by the speed limits established. The driving scenario, performed in daylight and under good weather conditions, consisted of 3 main sections, each with its own speed limit and lane configurations. The first section was a dual carriageway (with two lanes of traffic in each direction) of $4.5 \mathrm{~km}$ long, $120 \mathrm{~km} / \mathrm{h}$, no buildings, moderate traffic, and with a gentle curve. The second section was a winding mountain road of one-lane single carriageway $6 \mathrm{~km}$ long, with variable speed limit of $40 \mathrm{~km} / \mathrm{h}$ to $90 \mathrm{~km} / \mathrm{h}$, no buildings, and moderate traffic. The third section was an inner-city circuit $2 \mathrm{~km}$ long, a variable speed limit of $40-50 \mathrm{~km} / \mathrm{h}$, several intersections or roundabouts with traffic signals, many buildings, 16 pedestrians, and moderate traffic. The scenario used had identical traffic flow and the same number of peripheral events for all participants.

\subsubsection{Procedure}

Before the experiment, all participants received at least 2 sessions of training using the driving simulator with a similar scenario to those used in the experimental drives (without traffic or pedestrians) in order to minimize the impact of possible learning effects.

Each participant was tested under a baseline driving condition (without distraction), and a texting condition (WhatsApp messages) while driving. During driving (texting condition), participants received several WhatsApps with general questions (e.g. "What is the eleventh month of the year?") and were required to answer by means of composing another WhatsApp, which could occur in real life. A total of 6 WhatsApps were sent, all of similar length (30-55 characters), with one composed in the $2.8 \mathrm{~km}$ of driving, one in the $5.8 \mathrm{~km}$, one in the $8.5 \mathrm{~km}$, one in the $10.1 \mathrm{~km}$, one in the $13.3 \mathrm{~km}$, and one in the $14 \mathrm{~km}$ (See Appendix A). The smartphone was situated to the right side of the steering wheel on the stand and participants used their own personal smartphone to ensure that they were familiar with the functioning of the phone (Fig. 2). It should be noted that there were no restrictions on how they distributed their attention between texting and driving. Each of the two experimental drives was evaluated on different days to avoid fatigue.

All subjects were instructed to drive as they normally would and to simultaneously engage in the distracting task without allowing it to cause unsafe driving. If a participant showed any symptoms of simulator sickness (nausea, sweating or dizziness), the driving session was stopped and the subject was excluded from the study.

\subsubsection{Driving measures}

To assess driving performance, we considered the following dependent variables for analyses: mean speed, standard deviation of the angular velocity of the steering wheel, standard deviation of the lateral position (SDLP), time spent veering outside the lane, distance travelled veering outside the lane, number of times the driver veers outside the lane, and number of collisions. All variables were analysed under a baseline driving condition and with the use of the smartphone.

Data were recorded by the drive simulator program every $0.10 \mathrm{~s}$.

\subsection{Driver behaviour questionnaire (DBQ)}

The Driver Behaviour Questionnaire (DBQ) was used to measure aberrant driver behaviour (Reason et al., 1990) and has been used in numerous works (Cordazzo et al., 2016; Stephens and Fitzharris, 2016). Although the factorial structures of the DBQ vary between different cultures and nations, the factorial validity and reliability of the DBQ has recently been shown (Martinussen et al., 2013). The 30-item DBQ includes 3 items of aggressive violations, 11 items of ordinary violations, 8 items of lapses, and 8 items of errors (See Appendix B). The DBQ questionnaire has 30 acts on a 6 -point scale (from $1=$ "never" to $6=$ "nearly all the time") and the participants were asked to indicate how often they have committed each act when driving. The item scores were added together, with higher scores indicating more frequent aberrant behaviour.

\subsection{Statistical analysis}

All statistical procedures were performed using SPSS 20.0 (SPSS Inc., Chicago, IL). All measures were examined for normality (Kolmogorov-Smirnov test). An analysis of variance (ANOVA) with pairwise post hoc comparisons was used to identify differences in visual

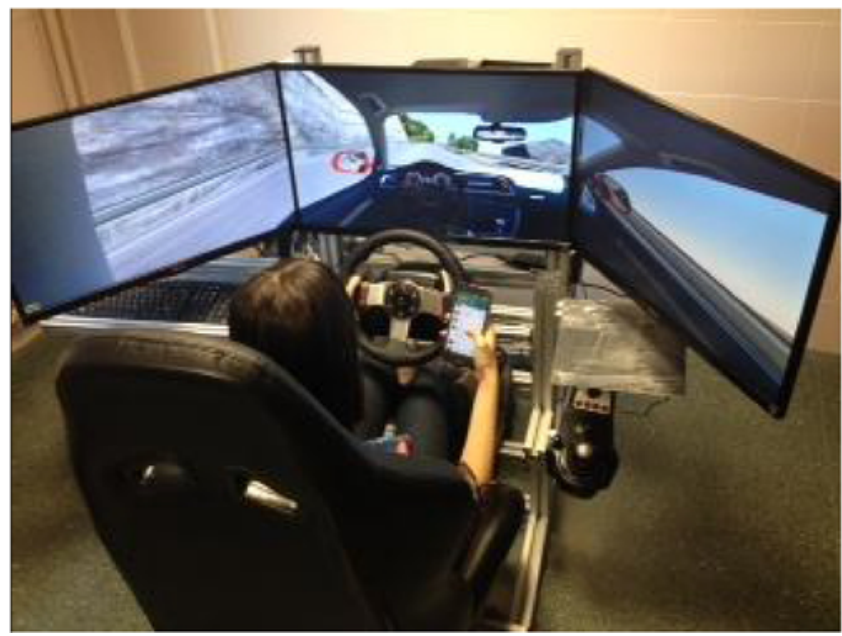

Fig. 2. The simulated environment used for the purposes of the study. 
performance across the four age groups. The correlation between vision measures of the visual function and driving performance was studied with Spearman's correlations.

Repeated-measures analyses of covariance (ANCOVA) were conducted for each dependent driving measure (normally distributed). In each ANCOVA, driving condition (i.e., baseline and distracted) served as within-subjects factor and age group served as between-subject factor, with vision measures as covariates. The $\mathrm{F}$ and probability values, the degrees of freedom, and the size effect $\left(\eta_{p}^{2}\right)$ were reported. After a significant $\mathrm{F}$ test, post hoc comparisons between age groups (Bonferroni corrected) were conducted.

A negative binomial model was developed to compare driving performance (number of times the driver veered outside the lane and number of collisions) across different age groups and driving conditions (baseline and distraction). The model used a log link function and negative binomial distribution. Repeated measures were accounted for by using generalized estimating equations (GEE). Also, visual measures were employed as covariates.

Finally, Kruskal Wallis test was also used to identify differences in tendency to commit aberrant driving behaviour across the four age groups.

Statistical significance was accepted at $\mathrm{p}<0.05$. All data were reported as mean \pm standard deviation.

\section{Results}

\subsection{Optical quality and visual performance}

Table 1 summarizes the results (mean \pm SD) for the OSI and straylight values for the four age groups. As can be seen, OSI and straylight increased with ageing, being significantly higher for drivers older than 55 years $(p<0.05)$. Higher values indicate a significant effect of intraocular scattering and more sensitivity to glare, limiting the visual function.

This can be seen in the Fig. 3, which presents the results of the average contrast sensitivity with glare (right image) and without (left image), measured with the CGT-1000 for all subjects (divided into age categories). Contrast sensitivity with glare was significantly lower in all groups for the six target sizes as compared to without glare.

Disability glare was assessed by measuring the effect of a glare source on contrast sensitivity. For this, disability glare was analysed by examining the difference in contrast sensitivity in the absence and presence of glare and was expressed as log contrast units lost with glare. A statistically significant difference between young adults (18-24 years) and older adults ( $>55$ years) was reflected only in the difference between the means $(\mathrm{p}=0.029)$ at 4 degrees of visual angle of target size, although older drivers had a higher disability glare than did the average of drivers for three target sizes: $6.3^{\circ}, 4^{\circ}$, and $2.5^{\circ}$.

Fig. 4 presents the results for binocular contrast-sensitivity function measured with the CSV-1000 test (as a function of the spatial frequencies considered) for all age groups. This figure reflects the deterioration in visual performance (a lower contrast-sensitivity function) for older drivers. The results in the binocular contrast-sensitivity function were significantly worse for older drivers than for young adult drivers (18-24 years) for 6 and $18 \mathrm{cpd}(\mathrm{p}=0.044)$.

\subsection{Driving performance}

Our results showed that, at least once in the past month, about $15.7 \%$ of drivers used handheld mobile phones while driving, about $44.9 \%$ reported having a hands-free mobile phone conversation, about $36.2 \%$ sent WhatsApp messages, and about $4.2 \%$ of them read emails and navigated. On the other hand, although our main aim was to evaluate driving performance while texting and not the ability to perform the secondary task, drivers aged 25-39 years spent significantly less time distracted reading/texting WhatsApp messages than did drivers older than 40 years of age, with the result that the drivers more than 40 years old did not answer c. $5 \%$ of the WhatsApp messages sent as opposed to $\sim 1 \%$ left unanswered by drivers $18-39$ years old. Nevertheless, it should be taken into account that before beginning the experimental measurements, all participants were instructed to drive safely and to simultaneously engage in the distracting task.

The associations between all vision measurements of the visual function and driving performance variables were tested. We found sig-

Table 1

Mean \pm SD for the OSI and retinal straylight $(\log (s))$ values for all age groups.

\begin{tabular}{|c|c|c|c|c|}
\hline & Age-groups & & & \\
\hline Parameters & Young adults (18-24 years) & Adults (25-39 years) & Middle-aged adults ( $40-54$ years) & Older adults ( $>55$ years) \\
\hline OSI & $0.54 \pm 0.34$ & $0.52 \pm 0.25$ & $0.62 \pm 0.23$ & $1.15 \pm 0.61$ \\
\hline $\log (s)$ & $0.95 \pm 0.13$ & $0.89 \pm 0.13$ & $0.97 \pm 0.12$ & $1.19 \pm 0.16$ \\
\hline
\end{tabular}
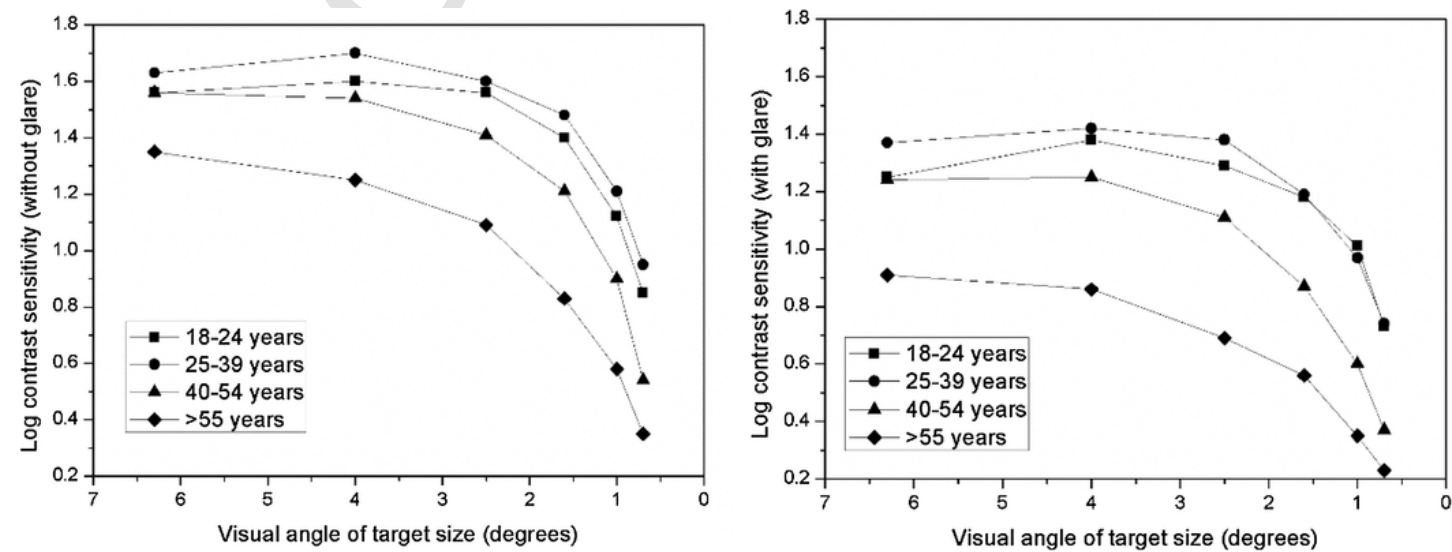

Fig. 3. Average contrast sensitivity, with glare (right image) and without (left image) measured with the CGT-1000 for all subjects (divided into age categories). 


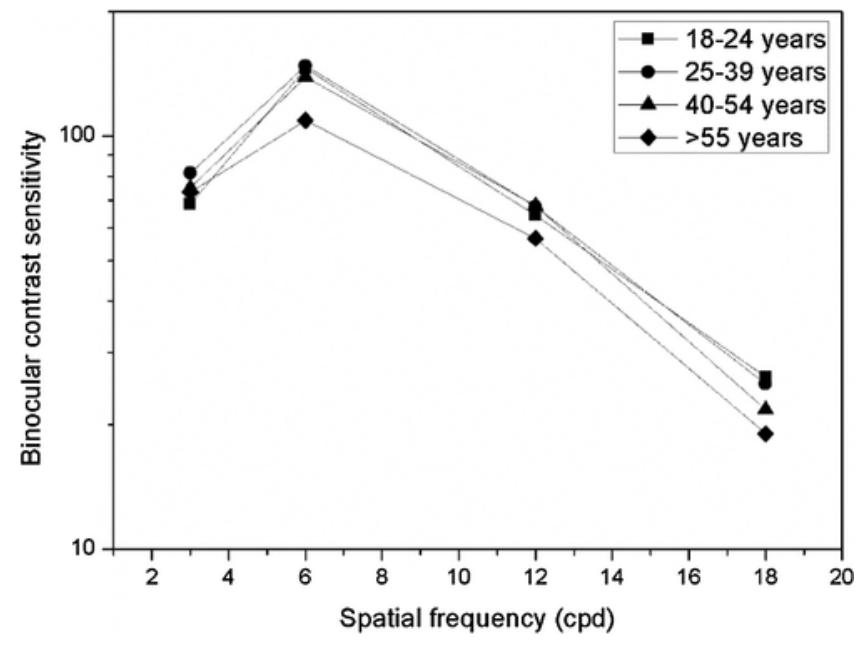

Fig. 4. Average binocular contrast-sensitivity function measured with the CSV-1000 test for all age groups.

nificant positive correlations between the retinal straylight $(\log (s)$ ) and the number of collisions $(r=0.30, p=0.010)$, the total distance travelled invading the opposite lane $(\mathrm{r}=0.29, \mathrm{p}=0.011)$, and with the SDLP $(r=0.25, p=0.031)$. On the other hand, there were significant negative correlations between the contrast sensitivity (CGT-1000) with glare and the total distance travelled invading the opposite lane $(\mathrm{r}=-0.25, \mathrm{p}=0.033)$. Lastly, there was a significant negative correlation between the contrast sensitivity (CGT-1000) and the number of collisions $(r=-0.33, p=0.004)$ and with the SDLP $(r=-0.28$, $\mathrm{p}=0.018$ ). Of all the vision measurements, straylight, and contrast sensitivity showed the strongest associations with the number of collisions.

\subsubsection{Driving performance on the dual carriageway}

Table 2 presents the descriptive statistics for the driving-performance measurements for the dual carriageway.

The ANCOVA analysis indicated a nonsignificant main effect of age or texting for the mean speed. However, there was a significant interaction Task $x$ Age $\left(F(3,66)=4.28, p=0.008, \eta_{p}^{2}=0.163\right)$, indicating that the speed was more reduced while texting for older drivers in comparison to other groups. Older drivers constituted the group that most slowed their velocity when using the smartphone, i.e. about $16.5 \%$ compared to $3.1 \%$ for the average of all the other drivers. The results also demonstrated that age group had a significant effect on the time spent veering outside the lane (on shoulder), $\left(\mathrm{F}_{(} 3,66\right)=4.31, \mathrm{p}=0.008$, $\eta_{\mathrm{p}}^{2}=0.164$ ). Older drivers spent by $\sim 150 \%$ more time outside the lane in comparison to the rest of the drivers (from 18 to 54 yrs.), for the two conditions (baseline and distraction). Also, for the number of times veering onto the shoulder, the negative binomial model revealed signif- icant main effects of age $\left[\chi^{2}(3)=37.10, \mathrm{p}<0.001\right]$ and distraction $\left[\chi^{2}(1)=26.45, \mathrm{p}<0.001\right]$. Older drivers veered off the lane a higher number of times compared to drivers aged between 18-39 years, with a notable effect of the smartphone

With regard to $S D$ of the angular velocity of the steering wheel, there was no significant effect of age or secondary task.

\subsubsection{Driving performance on the two-lane mountain road}

Table 3 presents the descriptive statistics for the driving performance measurements made for the two-lane mountain road. The ANCOVA analysis showed no significant main effect of age and secondary task for the mean speed.

On the other hand, drivers' ability to maintain a consistent lane position was measured by the standard deviation of lateral position (SDLP). Post hoc tests (Bonferronni corrected) indicated that older drivers had a higher standard deviation of the lateral lane position than did drivers $18-39$ years old $\left(\mathrm{F}(3,66)=5.03, \mathrm{p}=0.003, \eta_{\mathrm{p}}^{2}=0.186\right)$. Additionally, in all age groups an increase was found due to texting $\left(F_{(} 1,66\right)=9.16$, $\mathrm{p}=0.004, \eta_{\mathrm{p}}^{2}=0.122$ ). The older drivers' SDLP was $\sim 14 \%$ higher than that for the baseline average of all the other drivers, increasing to $\sim 29 \%$ under distraction, reflecting the impact of secondary tasks on driving performance.

The distance travelled in the opposite lane was significantly higher for older drivers $\left.\left(F_{3} 3,66\right)=4.62, p=0.005, \eta_{p}^{2}=0.173\right)$ than that for drivers 18-39 years old. Similarly, there was a significant main effect of age for the time spent invading the opposite lane $\left(\mathrm{F}_{(} 3,66\right)=3.72$, $\mathrm{p}=0.016, \eta_{\mathrm{p}}^{2}=0.145$ ). Older drives spent $\sim 89 \%$ more time spent invading the opposite lane than that for the average of all the other drivers, increasing to $162 \%$ when they drove while texting. The mean number of unintentional invasions of the opposite lane (times that any part of the driver's vehicle veered into the opposite lane) for the four age groups is shown in Fig. 5.

The negative binomial model showed a significant effect of age $\left[\chi^{2}(3)=28.87, \mathrm{p}<0.001\right]$ and also of distraction $\left[\chi^{2}(1)=36.83\right.$, $\mathrm{p}<0.001]$. Older drivers committed a higher number of invasions in comparison to that for the other groups of drivers, indicating a detrimental effect of the use of smartphone. Lastly, $S D$ of the angular velocity of the steering wheel showed a significant main effect of age. Younger drivers had a lower SD of the angular velocity of the steering wheel in comparison to that of middle-aged participants $\left(F_{(} 3,66\right)=3.45, p=0.021$, $\left.\eta_{\mathrm{p}}^{2}=0.136\right)$.

\subsubsection{City driving performance}

With regard to the mean velocity (Fig. 6), there was a significant interaction Task $x$ Age $\left(F(3,65)=4.59, \mathrm{p}=0.006, \eta_{\mathrm{p}}^{2}=0.175\right)$, indicating that, while texting WhatsApp messages, the older drivers drove slower in comparison to other drivers. Under distraction, older drivers reduced their average speed by $11.9 \%$ as oppose to $1.4 \%$ for the average of all the other drivers.

Table 2

Mean \pm SD for the driving parameters on the dual carriageway.

\begin{tabular}{|c|c|c|c|c|c|c|c|c|}
\hline & Baseline & & & & Distraction & & & \\
\hline $\begin{array}{l}\text { Driver's } \\
\text { age }\end{array}$ & $\begin{array}{l}\text { Mean speed } \\
(\mathrm{km} / \mathrm{h})\end{array}$ & $\begin{array}{l}\text { Number of } \\
\text { times veering } \\
\text { onto the } \\
\text { shoulder }\end{array}$ & $\begin{array}{l}\text { Time spent } \\
\text { on the } \\
\text { shoulder } \\
\text { (s) }\end{array}$ & $\begin{array}{l}\text { SD angular } \\
\text { velocity of } \\
\text { steering wheel } \\
(\mathrm{rad} / \mathrm{s})\end{array}$ & $\begin{array}{l}\text { Mean speed } \\
(\mathrm{km} / \mathrm{h})\end{array}$ & $\begin{array}{l}\text { Number of } \\
\text { times } \\
\text { veering } \\
\text { onto the } \\
\text { shoulder }\end{array}$ & $\begin{array}{l}\text { Time spent } \\
\text { on the } \\
\text { shoulder (s) }\end{array}$ & $\begin{array}{l}\text { SD angular } \\
\text { velocity of } \\
\text { steering } \\
\text { wheel } \\
(\mathrm{rad} / \mathrm{s})\end{array}$ \\
\hline $18-24$ & $115.94 \pm 8.88$ & $3.35 \pm 3.38$ & $2.58 \pm 2.82$ & $0.18 \pm 0.06$ & $114.15 \pm 10.55$ & $4.25 \pm 3.70$ & $3.56 \pm 3.52$ & $0.22 \pm 0.05$ \\
\hline $25-39$ & $117.53 \pm 7.09$ & $2.70 \pm 1.90$ & $2.24 \pm 1.97$ & $0.17 \pm 0.05$ & $113.56 \pm 10.24$ & $4.50 \pm 2.42$ & $4.21 \pm 3.02$ & $0.21 \pm 0.11$ \\
\hline $40-54$ & $113.13 \pm 7.93$ & $3.90 \pm 3.29$ & $4.21 \pm 5.09$ & $0.20 \pm 0.09$ & $108.31 \pm 11.90$ & $7.45 \pm 5.17$ & $8.60 \pm 6.01$ & $0.27 \pm 0.15$ \\
\hline$>55$ & $119.20 \pm 13.46$ & $6.20 \pm 3.86$ & $7.92 \pm 6.22$ & $0.30 \pm 0.26$ & $99.56 \pm 11.89$ & $9.00 \pm 3.82$ & $13.20 \pm 7.41$ & $0.39 \pm 0.25$ \\
\hline
\end{tabular}


Table 3

Mean \pm SD for the driving parameters on a two-lane mountain road.

\begin{tabular}{|c|c|c|c|c|c|c|c|c|c|c|}
\hline & Baseline & & & & & Distraction & & & & \\
\hline $\begin{array}{l}\text { Driver's } \\
\text { age }\end{array}$ & $\begin{array}{l}\text { Mean speed } \\
(\mathrm{km} / \mathrm{h})\end{array}$ & SDLP (m) & $\begin{array}{l}\text { Distance travelled } \\
\text { invading the opposite } \\
\text { lane (m) }\end{array}$ & $\begin{array}{l}\text { Time spent } \\
\text { invading the } \\
\text { opposite lane (s) }\end{array}$ & $\begin{array}{l}\text { SD angular velocity } \\
\text { of steering wheel } \\
(\mathrm{rad} / \mathrm{s})\end{array}$ & $\begin{array}{l}\text { Mean speed } \\
(\mathrm{km} / \mathrm{h})\end{array}$ & $\operatorname{SDLP}(\mathrm{m})$ & $\begin{array}{l}\text { Distance travelled } \\
\text { invading the } \\
\text { opposite lane (m) }\end{array}$ & $\begin{array}{l}\text { Time spent } \\
\text { invading the } \\
\text { opposite lane } \\
\text { (s) }\end{array}$ & $\begin{array}{l}\text { SD angular } \\
\text { velocity of } \\
\text { steering wheel } \\
(\mathrm{rad} / \mathrm{s})\end{array}$ \\
\hline $18-24$ & $55.29 \pm 2.26$ & $0.57 \pm 0.10$ & $309.95 \pm 200.17$ & $25.06 \pm 15.60$ & $0.61 \pm 0.26$ & $55.92 \pm 2.37$ & $0.64 \pm 0.14$ & $419.55 \pm 244.88$ & $29.80 \pm 20.07$ & $0.71 \pm 0.18$ \\
\hline $25-39$ & $55.43 \pm 2.07$ & $0.56 \pm 0.20$ & $305.15 \pm 238.80$ & $22.56 \pm 19.68$ & $0.69 \pm 0.22$ & $55.56 \pm 2.02$ & $0.61 \pm 0.10$ & $485.50 \pm 299.13$ & $32.76 \pm 20.35$ & $0.69 \pm 0.27$ \\
\hline $40-54$ & $55.48 \pm 2.23$ & $0.59 \pm 0.09$ & $487.47 \pm 351.57$ & $32.93 \pm 21.50$ & $0.83 \pm 0.36$ & $53.61 \pm 3.85$ & $0.72 \pm 0.12$ & $771.99 \pm 552.79$ & $57.01 \pm 37.18$ & $0.92 \pm 0.34$ \\
\hline$>55$ & $56.61 \pm 2.60$ & $0.65 \pm 0.13$ & $668.36 \pm 388.45$ & $50.69 \pm 28.76$ & $0.79 \pm 0.27$ & $52.44 \pm 3.40$ & $0.85 \pm 0.13$ & $1396.94 \pm 922.81$ & $104.46 \pm 59.73$ & $1.00 \pm 0.38$ \\
\hline
\end{tabular}




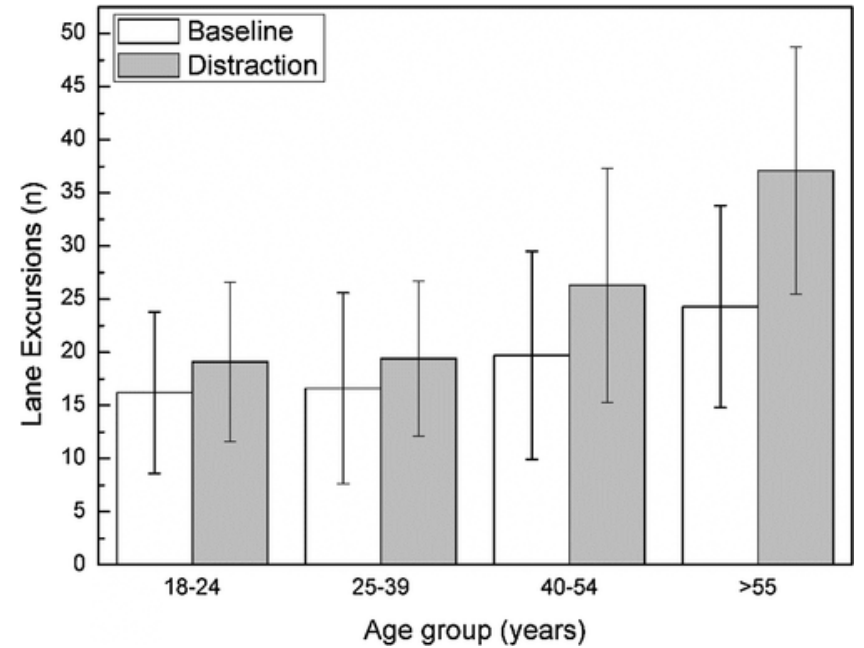

Fig. 5. Average number of times the driver veers outside the lane in all groups between the baseline and distraction driving.

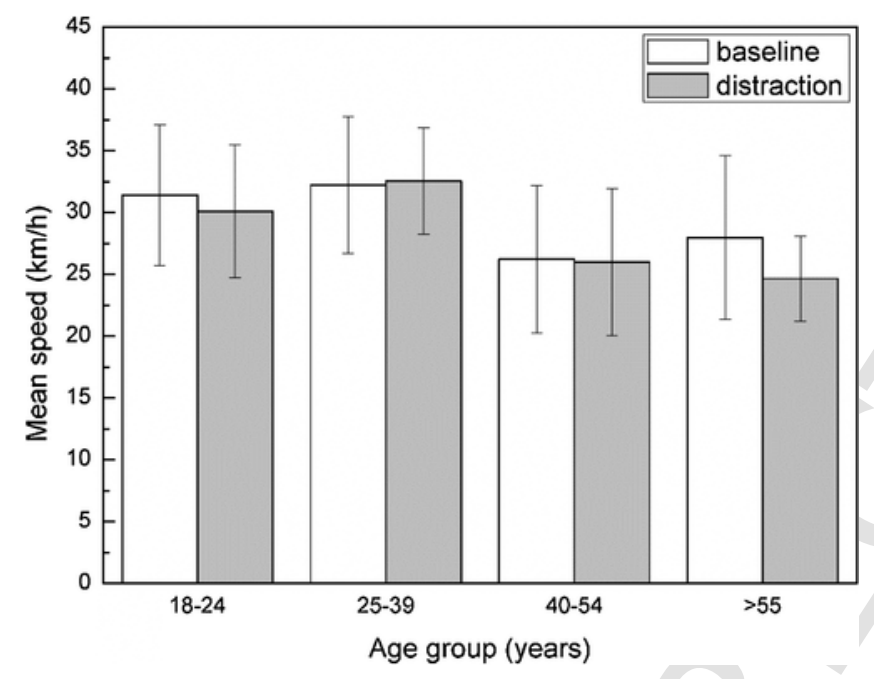

Fig. 6. Mean speed $(\mathrm{km} / \mathrm{h})$ in city streets for the baseline and distraction conditions.

Lastly, we also analysed the average number of collisions that occurred in the complete circuit (dual carriageway, mountain road, and city streets) under baseline and distraction conditions (Fig. 7).

The negative effect of the using the smartphone during driving proved evident, as this raised the number of collisions in all the groups of drivers (by $8.3 \%$ for young adults, $25.0 \%$ for adults, $80.5 \%$ for middle-aged adults, and $134.5 \%$ for older drivers). The negative binomial model revealed a significant main effect of age $\left[\chi^{2}(3)=10.91\right.$, $\mathrm{p}=0.012]$ and also of distraction $\left[\chi^{2}(1)=5.88, \mathrm{p}=0.015\right]$. Thus, texting while driving caused older drivers to have a higher number of collisions with respect to the other age groups. Also, older drivers had about 93\% more collisions than the average of drivers when participants were texting WhatsApp messages while driving (dotted line).

\subsection{Subjective driving performance (DBQ)}

Table 4 shows the means scores for each of the individual items relating to violations, errors, and lapses in the Driver Behaviour Questionnaire (DBQ) among drivers in four different age groups.

The most common behaviour was from the Ordinary Violations subscale: "driving while looking at a map or GPS device, changing the radio

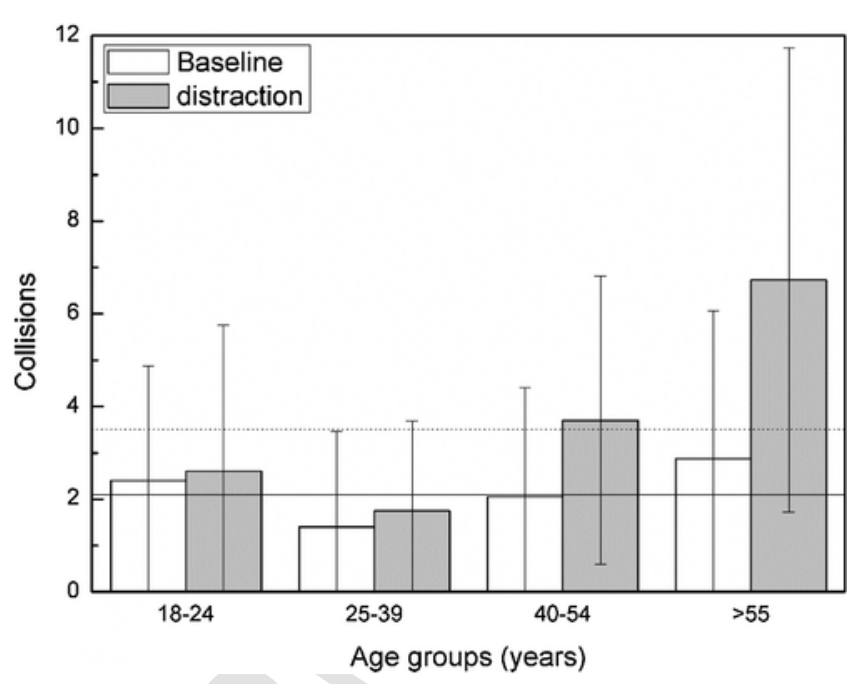

Fig. 7. Average number of collisions under the baseline and distraction conditions. Solid line indicates the mean collisions for the average of drivers at baseline. Dotted line indicates the mean collisions for the average of drivers texting WhatsApp messages while driving.

station, etc." The least common behaviour was from the Aggressive Violations subscale: "becoming angry at other drivers and pursuing them to express anger". "Braking too quickly on a slippery road" was the most frequent error for drivers aged from 18 to 54 years. However, "failing to notice pedestrians crossing when turning into a side street from a main street" was the most frequent error for drivers older than 55 years. "Getting into the wrong lane approaching a roundabout or intersection" was the most frequent lapse for drivers aged from 18-24 years and from 40-54 years. "Realizing that you have no clear recollection of the road along which you have just been travelling" was the most frequent lapse for drivers aged from 25-39 years. Lastly, "misreading signs and exiting from a roundabout on the wrong road" was the most frequent lapse for drivers older than 55 years.

Of the four subscales, the highest mean scores was for Ordinary Violations $(1.66 \pm 0.16)$, followed by Lapses $(1.63 \pm 0.03)$, Aggressive Violations $(1.56 \pm 0.09)$, and then Errors $(1.34 \pm 0.02)$. The scores for the current sample were lower than found by Stephens and Fitzharris (2016) who obtained the DBQ responses of a sample representative of the Australian population. These authors reported mean scores of $1.85 \pm 0.60$ for Lapses, $1.77 \pm 0.67$ for Aggressive Violations, $1.72 \pm 0.61$ for Violations and $1.44 \pm 0.49$ for Errors.

Drivers aged 18-24 years had the highest mean scores for the subscale of Ordinary Violations. Drivers aged 25-39 had the highest mean scores for the Aggressive Violations subscale followed by those older than 55 years. Drivers aged $40-54$ years had the highest mean scores for the Lapses subscale. Lastly, mean scores for errors were similar for all groups with "Braking too quickly on a slippery road" being the most frequent error among drivers (Fig. 8).

The scores showed statistically significant differences for the items from the Ordinary Violation subscale: "driving while looking at a map or GPS device, changing the radio station, etc." and "racing away from traffic lights to beat the driver next to you" with the highest score for drivers aged 18-24 years. For the Lapses subscale: "forgetting where the car was left in a car park" and "realizing that you have no clear recollection of the road along which you have just been travelling" younger adults (25-39 years) and middle- aged adults (40-54 years) drivers reported the highest estimated means, with significant differences with respect to older drivers $(\mathrm{p}<0.05)$. 
Table 4

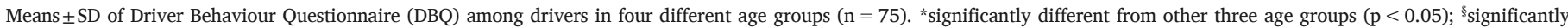
different from older drivers ( $\mathrm{p}<0.05)$; "significantly different from adults (25-39 years) and middle-aged adults $(40-54$ years) ( $\mathrm{p}<0.05)$

\begin{tabular}{|c|c|c|c|c|}
\hline Items & $\begin{array}{l}18-24 \text { years } \\
\mathrm{n}=20\end{array}$ & $\begin{array}{l}25-39 \text { years } \\
\mathrm{n}=20\end{array}$ & $\begin{array}{l}40-54 \text { years } \\
\mathrm{n}=20\end{array}$ & $\begin{array}{l}>55 \text { years } \\
\mathrm{n}=15\end{array}$ \\
\hline \multicolumn{5}{|l|}{ Aggressive violations } \\
\hline Sounding the horn to indicate annoyance with another road user & $1.50 \pm 0.69$ & $1.85 \pm 0.67$ & $1.60 \pm 0.50$ & $1.93 \pm 0.73$ \\
\hline Becoming angry at other drivers and pursuing them to express anger & $1.00 \pm 0.00$ & $1.10 \pm 0.31$ & $1.00 \pm 0.00$ & $1.07 \pm 0.27$ \\
\hline Getting angry at a certain type of driver and expressing anger in any manner & $1.80 \pm 1.06$ & $2.32 \pm 1.20$ & $1.90 \pm 0.72$ & $1.62 \pm 0.65$ \\
\hline \multicolumn{5}{|l|}{ Ordinary violations } \\
\hline Pulling out of a junction so far that the driver with right of way has to stop and let you go & $1.75 \pm 0.97$ & $1.30 \pm 0.47$ & $1.30 \pm 0.47$ & $1.21 \pm 0.43$ \\
\hline Driving faster than the speed limit in a playground or school zone & $2.15 \pm 0.99$ & $1.90 \pm 0.72$ & $1.70 \pm 0.57$ & $1.57 \pm 0.57$ \\
\hline $\begin{array}{l}\text { Staying in a motorway lane that you know will be closed ahead before forcing your way into the } \\
\text { other lane at the last minute }\end{array}$ & $1.25 \pm 0.44$ & $1.60 \pm 0.60$ & $1.35 \pm 0.59$ & $1.21 \pm 0.43$ \\
\hline Driving while looking at a map or GPS device, changing the radio station, etc. & $3.85 \pm 1.63^{\S}$ & $3.55 \pm 1.73$ & $2.95 \pm 1.28$ & $2.36 \pm 0.84$ \\
\hline Racing away from traffic lights to beat the driver next to you & $2.00 \pm 0.86^{*}$ & $1.30 \pm 0.47$ & $1.35 \pm 0.49$ & $1.33 \pm 0.62$ \\
\hline Driving so close to the car in front that it would be difficult to stop in an emergency & $1.80 \pm 1.28$ & $1.55 \pm 0.61$ & $1.55 \pm 0.51$ & $1.36 \pm 0.50$ \\
\hline Crossing an intersection knowing that the traffic lights have already changed against you & $1.15 \pm 0.37$ & $1.25 \pm 0.44$ & $1.29 \pm 0.47$ & $1.29 \pm 0.47$ \\
\hline Driving faster than the speed limit & $2.05 \pm 1.05$ & $2.00 \pm 0.73$ & $1.85 \pm 0.67$ & $1.71 \pm 0.47$ \\
\hline Talking on your hand-held cell phone while driving & $1.70 \pm 1.30$ & $1.55 \pm 0.61$ & $1.50 \pm 0.51$ & $1.36 \pm 0.50$ \\
\hline Texting messages, email, etc. while driving & $1.45 \pm 0.76$ & $1.50 \pm 0.61$ & $1.15 \pm 0.37$ & $1.00 \pm 0.00$ \\
\hline Eating or drinking while driving & $1.45 \pm 0.76$ & $1.55 \pm 0.51$ & $1.55 \pm 0.61$ & $1.57 \pm 0.65$ \\
\hline \multicolumn{5}{|l|}{ Errors } \\
\hline $\begin{array}{l}\text { In the queue to turn onto a main road, paying such close attention to the main stream of traffic that } \\
\text { you nearly hit the car in front of you }\end{array}$ & $1.35 \pm 0.49$ & $1.37 \pm 0.50$ & $1.35 \pm 0.49$ & $1.14 \pm 0.36$ \\
\hline $\begin{array}{l}\text { Failing to notice that pedestrians are crossing when you are turning into a side street from a main } \\
\text { road }\end{array}$ & $1.50 \pm 0.76$ & $1.45 \pm 0.51$ & $1.30 \pm 0.47$ & $1.57 \pm 0.94$ \\
\hline Failing to check your rear-view mirror before pulling out, changing lanes, etc. & $1.25 \pm 0.44$ & $1.40 \pm 0.60$ & $1.35 \pm 0.49$ & $1.29 \pm 0.61$ \\
\hline Braking too quickly on a slippery road & $1.60 \pm 0.68$ & $1.65 \pm 0.49$ & $1.60 \pm 0.50$ & $1.53 \pm 0.52$ \\
\hline On turning right/left nearly hitting a cyclist who has come up on your inside & $1.20 \pm 0.41$ & $1.25 \pm 0.44$ & $1.55 \pm 0.51$ & $1.21 \pm 0.43$ \\
\hline Missing "Give Way" signs and narrowly avoiding colliding with traffic having right of way & $1.30 \pm 0.47$ & $1.30 \pm 0.47$ & $1.20 \pm 0.41$ & $1.31 \pm 0.48$ \\
\hline Attempting to overtake someone that you had not noticed to be signalling a turn in front of you & $1.05 \pm 0.22$ & $1.20 \pm 0.41$ & $1.25 \pm 0.55$ & $1.15 \pm 0.38$ \\
\hline Underestimating the speed of an oncoming vehicle when you are overtaking & $1.55 \pm 0.83$ & $1.20 \pm 0.41$ & $1.25 \pm 0.44$ & $1.14 \pm 0.36$ \\
\hline \multicolumn{5}{|l|}{ Lapses } \\
\hline Hitting something that you had no previously seen when reversing & $1.20 \pm 0.41$ & $1.20 \pm 0.41$ & $1.50 \pm 0.51$ & $1.36 \pm 0.50$ \\
\hline $\begin{array}{l}\text { Intending to drive to destination A, you find yourself approaching destination B, because the latter } \\
\text { is your more usual destination }\end{array}$ & $1.84 \pm 0.69$ & $1.75 \pm 0.55$ & $2.05 \pm 0.61$ & $1.64 \pm 0.50$ \\
\hline Getting into the wrong lane approaching a roundabout or intersection & $1.95 \pm 1.19$ & $1.80 \pm 0.52$ & $2.05 \pm 0.61$ & $1.70 \pm 0.70$ \\
\hline $\begin{array}{l}\text { Switching on one item, such as the headlights, when you meant to switch on another, such as the } \\
\text { wipers }\end{array}$ & $1.45 \pm 0.69$ & $1.40 \pm 0.68$ & $1.15 \pm 0.37$ & $1.29 \pm 0.47$ \\
\hline Attempting to drive away from the traffic lights in third gear & $1.50 \pm 0.69$ & $1.40 \pm 0.50$ & $1.53 \pm 0.61$ & $1.57 \pm 1.34$ \\
\hline Forgetting where the car was left in a car park & $1.60 \pm 0.68$ & $1.85 \pm 0.75$ & $1.95 \pm 0.69$ & $1.21 \pm 0.43^{\ddagger}$ \\
\hline Misreading the signs and exiting from a roundabout on the wrong road & $1.85 \pm 0.67$ & $1.89 \pm 0.81$ & $1.84 \pm 0.38$ & $2.00 \pm 0.68$ \\
\hline Realizing that you have no clear recollection of the road along which you have just been travelling & $1.70 \pm 0.80$ & $1.95 \pm 0.69^{\S}$ & $1.75 \pm 0.72$ & $1.21 \pm 0.43$ \\
\hline
\end{tabular}

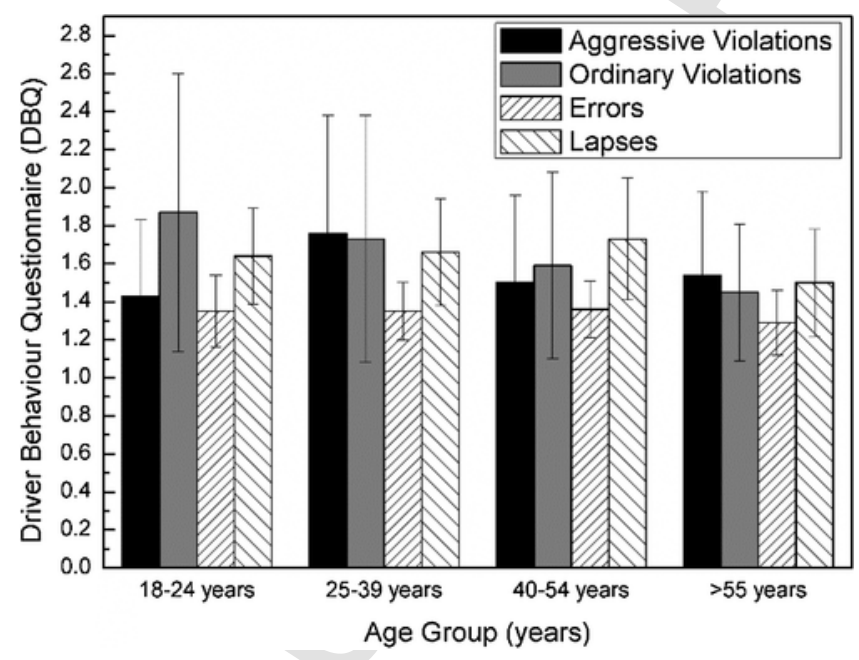

Fig. 8. Mean scores for each subscale of Driver Behaviour Questionnaire (DBQ) for each age group of drivers.

\section{Discussion}

In recent years, the surge in smartphone use and, therefore in the use of cell-phone applications such as WhatsApp has led to abuse, with a rise in the percentage of drivers of all ages who engage in texting or speaking into their handheld device (Dirección General de Tráfico, 2016). However, texting and driving are both mainly visual tasks and one of the most important causes of the vulnerability in older drivers is vision, which is one of the most vital sensory mechanisms in driving tasks. Aging causes a number of physiological changes in ocular structures that worsen visual performance and optical quality (Artal et al., 1993; Martínez-Roda et al., 2016; Owsley et al., 1983), contributing to a high risk of traffic accidents (Kimlin et al., 2017).

This study compares the effect of new forms of communication (e.g. texting WhatsApp messages) on driving performance through different age groups, since safe driving requires effective visual functions as well as cognitive skills. For visual performance, according to our results, older drivers had more deteriorated optical quality, with a higher level of intraocular scattering (Table 1). The results of the present study also showed that older drivers had less contrast sensitivity than did the other driver age groups, and that this parameter diminished significantly in the presence of glare (Fig. 3), resulting in greater glare disability for older drivers.

These functional changes occurring with age can affect driving performance. Thus, abnormalities in some of these functions have been correlated with increased traffic accidents. Evidence suggests that reduced contrast sensitivity and increased problems with glare degrade driving ability, especially in dim settings, reducing the number of traffic signs recognized, the ability to detect road hazards or pedestrians, even when drivers' visual acuity meets commonly adopted levels of vi- 
sual acuity required for driver license (Kimlin et al., 2017; Wood et al., 2012). In our study, older drivers, and therefore with greater visual impairment, invaded both the opposite lane and the shoulder significantly more often and for more time than did younger drivers. Furthermore, they proved to have less control of the steering wheel and thus less ability to maintain a consistent lane position, and consequently they had more accidents. Nonstandard vision tests such as the level of straylight and the contrast sensitivity (with and without glare) were correlated with a higher number of collisions, increased distance driven outside the lane and a higher standard deviation of lateral position, these being considered useful predictors of driving performance. These results support those of a previous works showing that a lower contrast sensitivity and a higher sensitivity to glare contributed to the elevated risk of crashes (Kimlin et al., 2017; Wood et al., 2009).

In addition to physical and cognitive changes that are associated with ageing and that can affect driving ability, deficits in visual attention increase accident risk (Owsley et al., 1998). An important source of driver distraction are secondary tasks which include eating, drinking, talking on the phone or to a passenger, and interacting with in-vehicle information, entertainment, or control systems (Fofanova and Vollrath, 2012). As mentioned above, smartphones represent an important part of modern life. Thus, our results have shown that about $36.2 \%$ of participants sent WhatsApp messages while driving, and about $4.2 \%$ of them read emails and navigated, data that indicate that despite that Spanish traffic laws prohibit the use of hand-held mobile phones while driving, it is still common to see individuals using the smartphone while driving (Dirección General de Tráfico, 2016).

In the current study, it was observed that, in general, participants drove more slowly when distracted by texting WhatsApp messages, the older drivers reducing their velocity the most while texting (about $16.5 \%$ or $11.9 \%$ in dual carriageway or city streets, respectively). Yannis et al. (2014) reported that the mean speed while texting a SMS message was reduced by $45 \%$ on urban roads, a reduction greater than found in our study, although these authors analysed only the impact of texting on the behaviour of young drivers. Similarly, Liu and Ou (2011) observed that a complex hands-free cell-phone conversation had a significantly negative impact on driving behaviour, and drivers compensated by lowering their speed. However, Young et al. (2014) found that, compared to baseline driving or a reading condition, the mean speed increased when drivers wrote text messages, perhaps due to a lack of attention to speed monitoring while writing texts, a task associated with higher subjective workload scores than the reading condition. On the other hand, we observed that younger drivers slowed their driving speed least under distraction conditions, apparently because the perceived risk had little effect on younger driver's behaviour in texting while driving (Atchley et al., 2011).

In relation to the baseline condition, texting WhatsApp messages while driving also led to a detrimental effect on driving control, as evidenced by a higher number of unintentional lane excursions, and a higher standard deviation of lateral position. This effect was more pronounced in older drivers when driving in more complex settings, such as two-lane mountain roads or city streets, reflected by $\sim 29 \%$ higher SDLP and $\sim 72 \%$ more lane excursions than for the average of all the other drivers when retrieving and texting WhatsApp messages. The finding that older drivers are more affected by distraction agree with the results of other studies. Thus, Rumschlag et al. (2015) also found that as the driver's age rose, the percentage of lane excursions became greater. This negative effect was also reflected in the lower control of the steering wheel. Thus, the standard deviation of the angular velocity of the steering wheel during texting WhatsApp messages was higher than for the baseline condition, except in the city, where it increased only for drivers 40-54 years old. However, when the driver's age is taken into consideration, the results show that WhatsApp texting while driving again had a harmful effect on the oldest drivers. Our results are consistent with some studies demonstrating a negative effect of smartphone use on the steering position (Papadakaki et al., 2016).

The reduction of attention capabilities of older drivers implies that the simultaneous performance of texting while driving will also raise the risk of crashes (Owsley et al., 1998). Texting during driving led to a greater number of collisions, the driver's age having a notable effect (average number of collisions increased by $134.5 \%$ for older drivers when texting WhatsApp messages compared with a $8.3 \%$ increase for young drivers). Hence, the results reflect that as the age of the drive advances, the accident risk due to distraction notably increases. Yannis et al. (2014) also found that the accident probability was increased when reading and writing SMS messages comparing to free driving, but these researchers sampled only young drivers. Their results agree with those of earlier studies (Alosco et al., 2012; Drews et al., 2009). Our findings are also consistent with previous suggestions that drivers, especially older ones, reduce their speed when using a phone, but it cannot compensate for the increase in accident probability induced by texting (Yannis et al., 2014). A leading cause of poor driving performance is high visual demand involved in texting (Hosking et al., 2009; Yannis et al., 2014; Young et al., 2014).

Although some drivers may be aware of the associated risks involved with driving and using a mobile phone at the same time, a self-report survey indicated that the number of drivers who used their smartphone to make or receive calls was high (about 16\% handheld and $45 \%$ hands-free device). These results could indicate that currently there is a greater number of drivers that more frequently prefer to use hand-free devices when driving. This fact remains worrying, since some works have concluded that the use of a hands-free device is no less hazardous than using a hand-held phone (Liu and Ou, 2011). Fofanova and Vollrath (2012) showed that middle-aged drivers were more likely to report engaging in certain distracting activities such as using a mobile phone than older drivers ( $20.7 \%$ and $7.8 \%$, respectively). We found that texting while driving was more frequent for the drivers aged 25-39 years followed by young drivers (18-24 years). However, other types of distraction were more common for the older group, such as eating or drinking while driving (Table 4).

In our study, people reported having a hands-free mobile phone conversation (45\%) more frequently than sending a WhatsApp message (36\%), as occurred in the study by Gras et al. (2007). The data found here are considerably higher than reported in Canada, with some $27 \%$ of drivers reported texting while driving (Tucker et al., 2015) or in Australia with $12.4 \%$ (Wales, 2006). A possible explanation is that using applications WhatsApp is increasing very rapidly in the population, including while driving.

Despite that the distraction negatively affected driving performance, younger drivers (18-24 years) scored a higher mean for ordinary violations especially for driving while looking at a map or GPS device, changing the radio station, etc., which was significantly higher than for older drivers. Getting angry at a certain type of driver and expressing anger was the second most frequent violation among drivers of 25-39 years of age, who proved to be the most aggressive group at the wheel. The speed limit violation was the third key item of violations, the youngest drivers most often being the offenders. These self-reported data indicated that younger drivers had a higher risk of deliberately violating safe driving practices, reflecting that they could need other means to change their driving style than drivers performing unintentional lapses/errors, as there is different underlying mechanism and different reason behind the two phenomena (Martinussen et al., 2013).

For errors, i.e. unintended behaviour, no significant differences were found among the different age groups, although older drivers had the lowest mean scores in this subscale perhaps because greater driving experience improves the level of driving skills (Gregersen, 1996). However, there was a significant difference observed in lapses, particularly in "forgetting where the car was left in a car park" and "realizing that you 
have no clear recollection of the road along which you have just been travelling", with a higher mean scores in younger adults (25-39 years) and middle-aged adults (40-54 years). Nevertheless, lapses are unintentional slips in memory or attention that do not on their own lead to an increased risk of crash involvement.

The mean scores for each subscale were lower than found by Stephens and Fitzharris (2016), indicating that, as in other studies, different countries differ in aberrant driver behaviour even for drivers of the same country, where aspects such as age, gender, or socio-economic characteristics may influence the driver's responses (Martinussen et al., 2013).

These results reflect that, according to the scores found on the questionnaires, younger drivers constituted the highest risk group for accidents, due to their behaviour. This might indicate that they overestimate their driving capacity during distraction. However, the objective results indicated a significant main effect of age on simulated driving performance, with a stronger deterioration in older drivers, implying a greater accident risk due to the use of applications such as WhatsApp during driving.

There are a number of possible methodological limitations with this study. One is that, despite having examined the effects of texting on driving performance among age groups in a wide range of driving conditions (dual carriageway, mountain road of one-lane single carriageway, and inner-city), the findings refer to a driving simulator, making it impossible to capture all the real-world dynamics of driving. However, many studies have demonstrated the validity of driver simulators, indicating that their use provided the most ethical way to conduct studies, ensuring safety in all situations. (Collet et al., 2010).

Another limitation is the lack of results that examine the effect of texting on driving performance by gender, due to the difficulty of finding females who completed the study, as most had to be excluded for showing symptoms of simulator sickness.

On the other hand, although the main objective was to evaluate the effect of texting WhatsApp on driving performance on drivers of different ages, it would have been informative to take into account as a factor the overall time that the participants took to complete the distracting task (to read/send a message). A higher percentage of texting time would increase driving errors. Nevertheless, our results also show that texting has a main effect on the standard deviation of the lateral position, the number of times the driver veers outside the lane, and the collisions, even among the younger drivers.

Due to the ageing of the population and the extended use of applications such as WhatsApp, which permits real-time text messages to be sent at no cost, the number of drivers that use a smartphone while driving is likely to increase, even among the older population. Therefore, because of the fundamental role of vision in driving, the findings of this study are of critical interest, showing that nonstandard vision tests, such as the measurement of the contrast sensitivity and the level of retinal straylight, could be useful predictors of the driving performance. Hence, even when the visual acuity is much greater than the minimum limit required by driving regulations, it would be recommendable to include other vision tests in the examination for driver licensing, thereby raising the awareness of older drivers regarding their visual limitations, and thereby encouraging them to adopt the necessary compensatory measures to maintain driving safety.

Given that all participants in the current study were healthy drivers, future studies could examine the driving performance in a sample with participants with greater loss of vision or those affected by ocular pathologies in order to reach a better understanding of the interactions between visual and driving factors, since visual impairment can play a vital role in safety road. In addition, for greater comprehension of the risks of distracted driving, we also recommend examining the effect of texting on simulated driving among age groups including factors such as the overall time engaged in the distractive task and/or the glance behaviour.

\section{Conclusions}

In summary, because the ageing population has increased the number of elderly drivers and because of the widespread use of the smartphone while driving (and more specifically certain applications such as WhatsApp), this cause of distraction has begun to be common in groups other than the youngest drivers. The results of this study suggest that texting WhatsApp messages while driving significantly impairs driving performance, with older drivers being the group most adversely affected, despite that they use WhatsApp as a common form of communication. This negative effect is observed especially when they drive in challenging settings such as two-lane mountain roads and city streets, despite the compensatory mechanism of reducing driving speed. Therefore, we deem it necessary to include nonstandard vision tests, such as the measurement of the contrast sensitivity and the level of retinal straylight, in the visual examination for the driving license as these have shown a significant association with driving performance, since visual acuity in high contrast situations is a poor predictor of driving ability.

Lastly, it is vital to determine the key problem areas in driving and those that exert varying effects on drivers of different ages. Thus, it is important to raise the awareness of the youngest drivers of their behaviour behind the wheel as well as warning the oldest drivers of age-associated changes in vision that can pose risks during driving and that can notably increase during distractions, such as texting WhatsApp messages.

\section{Uncited reference}

National Center for Statistics and Analysis (2017)

\section{Acknowledgments}

This work was supported by Ministry of Economy and Competitiveness (Spain) and European Regional Development Fund (ERDF) (Grant FIS2013-42204-R), by Ministry of Economy and Competitiveness (Grant UNGR13-1E-1903) and by Ministry of Education, Culture and Sport (Spain) (Grant FPU15/05571). We also thank David Nesbitt for translating the text into English.

\section{Appendix A. Supplementary data}

Supplementary material related to this article can be found, in the online version, at doi:https://doi.org/10.1016/j.aap.2018.04.018.

\section{References}

Alosco, M.L., Spitznagel, M.B., Fischer, K.H., Miller, La., Pillai, V., Hughes, J., Gunstad, J., 2012. Both texting and eating are associated with impaired simulated driving performance. Traffic Inj. Prev. 13 (5), 468-475. https://doi.org/10.1080/15389588.2012. 676697.

Artal, P., Ferro, M., Miranda, I., Navarro, R., 1993. Effects of aging in retinal image quality. J. Opt. Soc. Am. A 10 (7), 1656-1662. https://doi.org/10.1364/JOSAA.10.001656.

Aslam, T.M., Haider, D., Murray, I.J., 2007. Principles of disability glare measurement: an ophthalmological perspective. Acta Ophthalmol. Scand. 85, 354-360. https://doi.org/ 10.1111/j.1600-0420.2006.00860.x.

Atchley, P., Atwood, S., Boulton, A., 2011. The choice to text and drive in younger drivers: behavior may shape attitude. Accid. Anal. Prev. 43 (1), 134-142. https://doi.org/10. 1016/j.aap.2010.08.003.

Bromberg, S., Oron-Gilad, T., Ronen, A., Borowsky, A., Parmet, Y., 2012. The perception of pedestrians from the perspective of elderly experienced and experienced drivers. Accid. Anal. Prev. 44 (1), 48-55. https://doi.org/10.1016/j.aap.2010.12.028.

Chaparro, A, Wood, J.M., Carberry, T., 2005. Effects of age and auditory and visual dual tasks on closed-road driving performance. Optom. Vis. Sci. 82 (8), 747-754. 
Collet, C., Guillot, A., Petit, C., 2010. Phoning while driving II: a review of driving conditions influence. Ergonomics 53 (5), 602-616. https://doi.org/10.1080/ 00140131003769092.

Coppens, J.E., Franssen, L., van Rijn, L.J., van den Berg, T.J.T.P., 2006. Reliability of the compensation comparison stray-light measurement method. J. Biomed. Opt. 11 (3), 34027. https://doi.org/10.1117/1.2209555.

Cordazzo, S.T.D., Scialfa, C.T., Ross, R.J., 2016. Modernization of the driver behaviour questionnaire. Accid. Anal. Prev. 87, 83-91. https://doi.org/10.1016/j.aap.2015.11. 016.

Deshmukh, S., 2015. Analysis of WhatsApp users and its usage worldwide. Int. J. Sci. Res. Publ. 5 (8), 2-4.

Diaz-Douton, F., Benito, A., Pujol, J., Arjona, M., Guell, J.L., Artal, P., 2006. Comparison of the retinal image quality with a hartmann-shack wavefront sensor and a double-pass instrument. Investig. Opthalmol. Vis. Sci. 47 (4), 1710. https://doi.org/10.1167/iovs. 05-1049.

Dirección General de Tráfico, 2016. Conducir sin redes. D.G.T., Madrid.

Drews, F.A., Yazdani, H., Godfrey, C.N., Cooper, J.M., Strayer, D.L., 2009. Text messaging during simulated driving. Hum. Factors 51 (5), 762-770. https://doi.org/10.1177/ 0018720809353319.

Fofanova, J., Vollrath, M., 2012. Distraction in older drivers - a face-to-face interview study. Saf. Sci. 50 (3), 502-509. https://doi.org/10.1016/j.ssci.2011.10.017.

Fraser, M.L., Meuleners, L.B., Lee, A.H., Ng, J.Q., Morlet, N., 2013. Which visual measures affect change in driving difficulty after first eye cataract surgery?. Accid. Anal. Prev. 58, 10-14. https://doi.org/10.1016/j.aap.2013.04.015

Freeman, E.E., Muñoz, B., Turano, K.A., West, S.K., 2006. Measures of visual function and their association with driving modification in older adults. Investig. Ophthalmol. Vis. Sci. 47 (2), 514-520. https://doi.org/10.1167/iovs.05-0934.

Gras, M.E., Cunill, M., Sullman, M.J.M., Planes, M., Aymerich, M., Font-Mayolas, S., 2007. Mobile phone use while driving in a sample of Spanish university workers. Accid. Anal. Prev. 39 (2), 347-355. https://doi.org/10.1016/j.aap.2006.08.006

Gregersen, N.P., 1996. Young drivers' overestimation of their own skill—an experiment on the relation between training strategy and skill. Accid. Anal. Prev. 28 (2), 243-250. https://doi.org/10.1016/0001-4575(95)00066-6.

Hosking, S.G., Young, K.L., Regan, M.A., 2009. The effects of text messaging on young drivers. Hum. Factors 51 (4), 582-592. https://doi.org/10.1177/0018720809341575.

Kimlin, J.A., Black, A.A., Wood, J.M., 2017. Nighttime driving in older adults: effects of glare and association with mesopic visual function. Investig. Opthalmol. Vis. Sci. 58 (5), 2796. https://doi.org/10.1167/iovs.16-21219.

Liu, Y.-C., Ou, Y.-K., 2011. Effects of age and the use of hands-free cellular phones on driving behavior and task performance. Traffic Inj. Prev. 12 (6), 550-558. https://doi. org/10.1080/15389588.2011.607197.

Martínez-Roda, J.A., Vilaseca, M., Ondategui, J.C., Aguirre, M., Pujol, J., 2016. Effects of aging on optical quality and visual function. Clin. Exp. Optom. 99 (6), 518-525. https: //doi.org/10.1111/cxo.12369.

Martínez-Roda, J.A., Vilaseca, M., Ondategui, J.C., Giner, A., Burgos, F.J., Cardona, G., Pujol, J., 2011. Optical quality and intraocular scattering in a healthy young population. Clin. Exp. Optom. 94 (2), 223-229. https://doi.org/10.1111/j.1444-0938.2010. 00535.x.

Martinussen, L.M., Hakamies-Blomqvist, L., Møller, M., Özkan, T., Lajunen, T., 2013. Age, gender, mileage and the DBQ: the validity of the driver behavior questionnaire in different driver groups. Accid. Anal. Prev. 52, 228-236. https://doi.org/10.1016/j.aap. 2012.12.036.

Michael, R., van Rijn, L.J., van den Berg, T.J.T.P., Barraquer, R.I., Grabner, G., Wilhelm, H., Coeckelbergh, T., Emesz, M., Marvan, P., Nischler, C., 2009. Association of lens opacities, intraocular straylight, contrast sensitivity and visual acuity in European drivers. Acta Ophthalmol. 87, 666-671. https://doi.org/10.1111/j.1755-3768.2008. 01326.x.

Mitzner, T.L., Boron, J.B., Fausset, C.B., Adams, A.E., Czaja, S.J., Dijkstra, K., Fisk, A.D., Rogers, W.A., Sharit, J., 2010. Older adults talk technology: technology usage and attitudes. Comput. Hum. Behav. 26 (6), 1710-1721. https://doi.org/10.1016/j.chb.2010. 06.020 .

National Center for Statistics and Analysis, 2017. Distracted Driving 2015. (Traffic Safety Facts Research Note. Report No. DOT HS 812 381). March National Highway Traffic Safety Administration, Washington, DC.

Ortiz, C., Castro, J.J., Alarcón, A., Soler, M., Anera, R.G., 2013. Quantifying age-related differences in visual-discrimination capacity: drivers with and without visual impairment. Appl. Ergon. 44 (4), 523-531. https://doi.org/10.1016/j.apergo.2012.11.006.

Owsley, C., Ball, K., McGwin, G., Sloane, M.E., Roenker, D.L., White, M.F., Overley, E.T., 1998. Visual processing impairment and risk of motor vehicle crash among older adults. JAMA 279 (14), 1083-1088.

Owsley, C., McGwin, G., 2010. Vision and driving. Vis. Res. 50 (23), 2348-2361. https:// doi.org/10.1016/j.visres.2010.05.021.
Owsley, C., Sekuler, R., Siemsen, D., 1983. Contrast sensitivity throughout adulthood. Vis Res. 23 (7), 689-699. https://doi.org/10.1016/0042-6989(83)90210-9.

Owsley, C., Stalvey, B.T., Wells, J., Sloane, M.E., McGwin Jr., G., 2001. Visual risk factors for crash involvement in older drivers with cataract. Arch. Ophthalmol. 119 (6), 881-887. https://doi.org/10.1001/archopht.119.6.881.

Papadakaki, M., Tzamalouka, G., Gnardellis, C., Lajunen, T.J., Chliaoutakis, J., 2016. Driving performance while using a mobile phone: a simulation study of Greek professional drivers. Transp. Res. Part F Traffic Psychol. Behav. 38, 164-170. https://doi. org/10.1016/j.trf.2016.02.006.

Pesudovs, K., 2007. Takagi glare tester CGT-1000 for contrast sensitivity and glare testing in normal individuals and cataract patients. J. Refract. Surg. 23 (5), 492-498.

Pomerance, G.N., Evans, D.W., 1994. Test-retest reliability of the CSV-1000 contrast test and its relationship to glaucoma therapy. Invest. Ophthalmol. Vis. Sci. 35 (9), 3357-3361.

Pope, C.N., Bell, T.R., Stavrinos, D., 2017. Mechanisms behind distracted driving behavior: the role of age and executive function in the engagement of distracted driving. Accid Anal. Prev. 98, 123-129. https://doi.org/10.1016/j.aap.2016.09.030.

Reason, J., Manstead, A., Stradling, S., Baxter, J., Campbell, K., 1990. Errors and violations on the roads: a real distinction?. Ergonomics 33 (10-11), 1315-1332. https:// doi.org/10.1080/0ss0140139008925335.

Romoser, M.R., Pollatsek, A., Fisher, D.L., Williams, C.C., 2013. Comparing the glance patterns of older versus younger experienced drivers: scanning for hazards while approaching and entering the intersection. Transp. Res. Part F Traffic Psychol. Behav. 16, 104-116. https://doi.org/10.1016/j.trf.2012.08.004.

Rumschlag, G., Palumbo, T., Martin, A., Head, D., George, R., Commissaris, R.L., 2015. The effects of texting on driving performance in a driving simulator : the influence of driver age. Accid. Anal. Prev. 74, 145-149. https://doi.org/10.1016/j.aap.2014.10. 009.

Shinar, D., Tractinsky, N., Compton, R., 2005. Effects of practice, age, and task demands, on interference from a phone task while driving. Accid. Anal. Prev. 37 (2), 315-326. https://doi.org/10.1016/j.aap.2004.09.007.

Stephens, A.N., Fitzharris, M., 2016. Validation of the driver behaviour questionnaire in a representative sample of drivers in Australia. Accid. Anal. Prev. 86, 186-198. https:// doi.org/10.1016/j.aap.2015.10.030.

Szlyk, J.P., Seiple, W., Viana, M., 1995. Relative effects of age and compromised vision on driving performance. Hum. Factors 37 (2), 430-436. https://doi.org/10.1518/ 001872095779064645 .

Tucker, S., Pek, S., Morrish, J., Ruf, M., 2015. Prevalence of texting while driving and other risky driving behaviors among young people in Ontario, Canada: evidence from 2012 and 2014. Accid. Anal. Prev. 84, 144-152. https://doi.org/10.1016/j.aap.2015 07.011 .

van den Berg, T.J.T.P., Coppens JE inventors, Konik, N.L., 2006. Akademie van Wetens Applicant. Method and Device for Measuring Retinal Straylight. European Patent EP 1659929. May 31.

Vilaseca, M., Peris, E., Pujol, J., Borras, R., Arjona, M., 2010. Intra- and intersession repeatability of a double-pass instrument. Optom. Vis. Sci. 87, 675-681. https://doi. org/10.1097/OPX.0b013e3181ea1ad3.

Wales, S., 2006. Modern Life Style - Research Phone Use and Crashes While Driving : a Representative Survey of Modern Life Style - Research 18511.

Wilson, F.A., Stimpson, J.P., 2010. Trends in fatalities from distracted driving in the United States, 1999 to 2008. Am. J. Public Health 100 (11), 2213-2219. https://doi. org/10.2105/AJPH.2009.187179.

Wood, J., Chaparro, A., Hickson, L., 2009. Interaction between visual status, driver age and distracters on daytime driving performance. Vis. Res. 49 (17), 2225-2231. https: //doi.org/10.1016/j.visres.2009.06.017.

Wood, J.M., Tyrrell, R.A., Chaparro, A., Marszalek, R.P., Carberry, T.P., Chu, B.S., 2012 Even moderate visual impairments degrade drivers' ability to see pedestrians at night. Invest. Ophthalmol. Vis. Sci. 53 (6), 2586-2592. https://doi.org/10.1167/iovs. 11-9083.

World Health Organization, 2011. Mobile Phone Use: A Growing Problem of Driver Distraction.

World Medical Association Declaration of Helsinki, 2001. Ethical principles for medical research involving human subjects. Bull. World Health Organ. 79, 373-374.

Yannis, G., Laiou, A., Papantoniou, P., Christoforou, C., 2014. Impact of texting on young drivers' behavior and safety on urban and rural roads through a simulation experiment. J. Saf. Res. 49, 25-31. https://doi.org/10.1016/j.jsr.2014.02.008.

Yannis, G., Laiou, A., Papantoniou, P., Gkartzonikas, C., 2016. Simulation of texting impact on young drivers' behavior and safety on motorways. Transp. Res. Part F Psychol. Behav. 41, 10-18.

Young, K.L., Rudin-Brown, C.M., Patten, C., Ceci, R., Lenné, M.G., 2014. Effects of phone type on driving and eye glance behaviour while text-messaging. Saf. Sci. 68, 47-54. https://doi.org/10.1016/j.ssci.2014.02.018. 